\title{
Surgical Management of Minimally Invasive Anterior Lumbar Interbody Fusion with Stand-Alone Interbody Cage for L4-5 Degenerative Disorders: Clinical and Radiographic Findings
}

\author{
Yasuo HIRONAKA, ${ }^{1}$ Tetsuya MORIMOTO, ${ }^{2}$ Yasushi MOTOYAMA, ${ }^{1}$ \\ Young-Su PARK, ${ }^{1}$ and Hiroyuki NAKASE ${ }^{1}$ \\ ${ }^{1}$ Department of Neurosurgery, Nara Medical University, Kashihara, Nara; \\ ${ }^{2}$ Department of Neurosurgery, Takai Hospital, Tenri, Nara
}

\begin{abstract}
Surgical treatment for degenerative spinal disorders is controversial, although lumbar fusion is considered an acceptable option for disabling lower back pain. Patients underwent instrumented minimally invasive anterior lumbar interbody fusion (mini-ALIF) using a retroperitoneal approach except for requiring multilevel fusions, severe spinal canal stenosis, high-grade spondylolisthesis, and a adjacent segments disorders. We retrospectively reviewed the clinical records and radiographs of 142 patients who received mini-ALIF for L4-5 degenerative lumbar disorders between 1998 and 2010 . We compared preoperative and postoperative clinical data and radiographic measurements, including the modified Japanese Orthopaedic Association (JOA) score, visual analog scale (VAS) score for back and leg pain, disc height (DH), whole lumbar lordosis (WL), and vertebral wedge angle (WA). The mean follow-up period was 76 months. The solid fusion rate was $90.1 \%(128 / 142$ patients). The average length of hospital stay was 6.9 days (range, 3-21 days). The mean blood loss was $63.7 \mathrm{ml}$ (range, 10-456 ml). The mean operation time was $155.5 \mathrm{~min}$ (range, 96-280 $\mathrm{min}$ ). The postoperative JOA and VAS scores for back and leg pain were improved compared with the preoperative scores. Radiological analysis showed significant postoperative improvements in DH, WL, and WA, and the functional and radiographical outcomes improved significantly after 2 years. The $2.8 \%$ complication rate included cases of wound infection, liquorrhea, vertebral body fractures, and a misplaced cage that required revision. Mini-ALIF was found to be associated with improved clinical results and radiographic findings for $\mathrm{L4-5}$ disorders. A retroperitoneal approach might therefore be a valuable treatment option.
\end{abstract}

Key words: anterior lumbar interbody fusion, circumferential fusion, degenerative lumbar spinal disorder, minimally invasive therapy

\section{Introduction}

Degenerative spinal disorders include disc hernia, canal stenosis, scoliosis, spondylosis, isthmic and degenerative spondylolisthesis, and vertebral compressed fractures. Surgical treatment for these diseases is controversial and there is insufficient evidence to recommend a standard approach. Many studies have reported clinical outcomes after surgical treatment of spinal degenerative disorders, and lumbar fusion is considered to be an acceptable option for treating disabling lower back pain.

The anterior approach to lumbar spine fusion

Received October 29, 2012; Accepted January 16, 2013 was initially described by Carpenter ${ }^{4)}$ and has been used subsequently with success. ${ }^{19,20)}$ Here we describe a retroperitoneal approach for levels L4-5which are applicable to minimally invasive anterior lumbar interbody fusion (mini-ALIF). ${ }^{32,33)}$ This method is advantageous because of the high fusion rates $^{2,9,13,16,17,23,26-29,31,32)}$ and the ability to resect the pain-generating intervertebral disc completely while sparing the posterior structures. ${ }^{46)}$ Moreover, ALIF has been reported to produce satisfactory clinical outcomes for lumbar degenerative disorders, even when it was not possible to understand the reason for lesions between intervertebral discs.

The present study retrospectively compared the preoperative and postoperative radiographical 
imaging and clinical outcomes for L4-5 degenerative lumbar spinal disorders according to the Japanese Orthopaedic Association (JOA) score (Table 1), the visual analog scale (VAS) score for back and leg pain, and the patient's degree of satisfaction with the operation.

\section{Materials and Methods}

A total of 323 patients with lumbar degenerative disorders from L1-S1 were operated at our institution and at the Osaka Police Hospital (Osaka) between 1998 and 2010. One hundred ninety-three of 323 patients performed the single-level stand-alone mini-ALIF. The device was implanted at L1-2 in 2 patients, at L2-3 in 3, at L3-4 in 38, at L4-5 in 142,

Table 1 Summary of the Japanese Orthopaedic Association system for classifying low-back and leg pain

\begin{tabular}{|c|c|}
\hline Category & Score \\
\hline \multicolumn{2}{|l|}{ Subjective symptoms of low back pain } \\
\hline Continuous severe pain & 0 \\
\hline Occasional severe pain & 1 \\
\hline Occasional mild pain & 2 \\
\hline None & 3 \\
\hline \multicolumn{2}{|l|}{ Leg pain, tingling, or both } \\
\hline Continuous severe symptoms & 0 \\
\hline Occasional severe symptoms & 1 \\
\hline Occasional slight symptoms & 2 \\
\hline None & 3 \\
\hline \multicolumn{2}{|l|}{ Walking ability } \\
\hline Able to walk $<10 \mathrm{~m}$ & 0 \\
\hline Able to walk $>100 \mathrm{~m}$ but $<500 \mathrm{~m}$ & 1 \\
\hline $\begin{array}{l}\text { Able to walk }>500 \mathrm{~m} \text {, but w/leg pain or } \\
\text { tingling }\end{array}$ & 2 \\
\hline Normal & 3 \\
\hline \multicolumn{2}{|l|}{ Clinical signs } \\
\hline \multicolumn{2}{|l|}{$\begin{array}{l}\text { Straight leg-raising test (including tight } \\
\text { hamstrings) }\end{array}$} \\
\hline$<30^{\circ}$ & 0 \\
\hline$>30^{\circ}$, but $<70^{\circ}$ & 1 \\
\hline Normal & 2 \\
\hline \multicolumn{2}{|l|}{ Sensory } \\
\hline Marked disturbance & 0 \\
\hline Slight disturbance (not subjective) & 1 \\
\hline Normal & 2 \\
\hline \multicolumn{2}{|l|}{ Motor } \\
\hline $\begin{array}{l}\text { Marked disturbance (manual muscle } \\
\text { testing Grade 3-0) }\end{array}$ & 0 \\
\hline $\begin{array}{l}\text { Slight disturbance (manual muscle testing } \\
\text { Grade } 4 / 5 \text { ) }\end{array}$ & 1 \\
\hline Normal & 2 \\
\hline
\end{tabular}

and at L5-S1 in 8 .

The study group comprised 142 patients (82 men and 60 women) with an average age \pm standard deviation (SD) of $64.3 \pm 12.0$ years (range, $24-83$ years) who underwent mini-ALIF for L4-5 disorders. All 142 patients followed the clinical and radiographical result at least 2 years postoperatively. The mean follow-up period was 76 months (range, 26-146.6 months). Fourteen of the 142 cases underwent previous surgery via a posterior approach (Table 2). The authors selected the artificial titanium cage, such as BAK $^{\circledR}$ cage (ZIMMER, Minneapolis, Minnesota, USA); Stabilis ${ }^{\circledR}$ cage (Stryker, Allendale, New Jersey, USA); and L-Varlock ${ }^{\circledR}$ cage (KISCO international, Saint-Priest, France). Twenty-five patients were operated using $\mathrm{BAK}^{\circledast}, 5$ using Stabilis ${ }^{\circledR}$, and 112 using L-Varlock $^{\circledast}$. BAK ${ }^{\circledast}$ and Stabilis ${ }^{\circledR}$ were used during the first 4 years period and L-Varlock ${ }^{\oplus}$ since 2003.

The selection criteria were as follows: diagnosis of a lumbar spinal degenerative disorder by way of a lesion, which causes sagittal alignment abnormality, intervertebral instability, disc height (DH) decrease, intervertebral foramen stenosis, and intractable discogenic pain; a minimum follow-up period of 2 years; chronic and persistent radiculopathy; loss of quality of life; progressive neurological deficits; and persistent and unremitting lower back pain for at least 3 months. Exclusion criteria were as follows: requiring multilevel fusions, severe spinal canal stenosis extending between many intervertebral discs, fixed spinal deformities; concomitant scoliosis of more than $15^{\circ}$, a compression fracture or instability at adjacent segments, and high-grade spondylolisthesis (more than Meyerding Grade 2). Patients with active abdominal infection, metabolic bone disease, notable cardiac disease, abdominal malignancy, or notable psychosocial dysfunction were also excluded.

Table 2 Summary of patient characteristics

\begin{tabular}{lc}
\hline Characteristic & \\
\hline Number of patients & 142 \\
Total level of fusion & 142 \\
Mean age in years (range) & 64.3 \\
& $(24-83)$ \\
Gender (male:female) & $82: 60$ \\
Mean follow-up (months) & 76 \\
Previous surgical cases & 14 \\
Diagnosis & \\
Disc diseases & 45 \\
Spondylolisthesis Grade 1 & 30 \\
Facet and foraminal disease & 28 \\
Multiple disease & 39 \\
\hline
\end{tabular}

Neurol Med Chir (Tokyo) 53, December, 2013 
Radiographic assessments were made by an independent observer. We performed radiological and clinical assessments postoperatively, including magnetic resonance imaging (MRI), dynamic radiography, myelography, myelographic computed tomography (CT), and three-dimensional CT angiography. Discography was performed when assessment of affection level was difficult, and adjacent-segment degeneration was defined by imaging. ${ }^{35)}$ Plain radiography was performed immediately after the operation and at $1,3,6,12$, and 24 months postoperatively to assess the anterior $\mathrm{DH}$; this was measured as the distance between the most anterior aspects of the endplates on the lateral view of a standing neutral plain radiograph. Radiological identification of lumbar arthrodesis was defined as follows: the absence of lucency around the threaded interbody implant, the presence of bridging bone incorporating the anterior bone graft, and the absence of movement $>3 \mathrm{~mm}$ on dynamic X-rays. ${ }^{11,29)}$ Fusion assessment was based on plain radiography at 6 , 12, and 24 months postoperatively, supplemented with the flexion-extension test showing the fusion sign of an artificial cage. When we will be able to recognize all the previous three points, we will decide to fuse in this union.

Patient clinical outcome was measured using the modified JOA scale and VAS pain scores for the back and leg. JOA evaluation was used to assess the state of subjective symptoms and clinical signs. We adapted JOA scores preoperatively and at 3, 6 , 12 , and 24 months postoperatively. The recovery change compared with preoperative scores was examined according to the JOA and VAS scores.

All patients of this study underwent single-level stand-alone mini-ALIF for using artificial titanium cages. A left-sided retroperitoneal approach was used for L4-5 lesions. All patients were treated with autogenous vertebral spur or apacerum powder. In the retroperitoneal approach, patients were placed in a lateral decubitus position on a radiolucent breaking table. The iliac crest was flexed over the table break, to open the space between the crest and the 12th rib. A 5 -cm skin incision was made after centering above the L4-5 disc level as confirmed by lateral fluoroscopy. After splitting the three layers of abdominal muscles (external and internal muscles of the abdomen and transverse abdominal muscle), the psoas muscle covering the vertebral body was accessed at the bottom via the retroperitoneal space. While keeping the thin peritoneum intact, the psoas muscle was gently retracted backward to expose the disc space anterolaterally. A discectomy was carried out through this space until the posterior longitudinal ligament was exposed. At the same time, the operators performed endplate preparation. Vertebral distraction was carried out by widening the disc space and adequately decompressing the nerve roots with a distractor. Two artificial titanium cages filled with apacerum powder and autologous bone were packed, one ventral to the other, into the intervertebral space. When the position of the cages was confirmed on an anteroposterior and lateral fluoroscope, a central screw was rotated to expand the cage height to enable it to engage in the disc space by pushing the vertebral body. ${ }^{34)}$

In all cases, sufficient discectomy was carried out to reveal the affected posterior longitudinal ligament directly. In the case of a reoperation including adjacent segment lesions after performing mini-ALIF, we operated on the other side to avoid injury to the peritoneum, retroperitoneum, organs and, main blood vessels.

Postoperative care will consist of a 2-day period of bed rest with head up position around $60^{\circ}$. After this period, patients will wear a flexible corset for 3 months and will be allowed to walk normally. If there is any preoperative motor weakness of lower extremities, they start to walk and exercise by physical and occupational therapist support at the same time.

Statistical analysis was performed using PASW Statistics 18 (SPSS Japan, Tokyo) analytical software. Preoperative and postoperative data were compared with the paired $t$-test. $\mathrm{p} \leq 0.05$ was considered statistically significant. Data are presented as mean \pm SD.

\section{Results}

The mean DHs were measured preoperatively; immediately after the operation; and 6, 12, and 24 months postoperatively; they were found to be sustained at statistically increased levels for a long postoperative period (Table 3). The mean vertebral wedge angle (WA) and lordosis differed significantly between the preoperative state and at the 2-year evaluation (Table 3).

Preoperative and postoperative JOA and VAS pain scores for the back and leg were also assessed and were found to have improved by the 2-year evaluation, with a statistically significant intergroup difference (Table 3). Of the 142 patients, 125 (88\%) were satisfied with their clinical result at the 2-year postoperative stage. This was particularly true for patients with failed back-surgery syndrome, all 14 of whom expressed satisfaction and had a good prognosis.

No incidences of severe and symptomatic pseudoarthrosis requiring revision occurred in this 
Table 3 Comparison of preoperative and 1- and 2-year postoperative radiographical assessments

\begin{tabular}{lrrrr}
\hline \multirow{2}{*}{ Variable } & Preoperative & \multicolumn{2}{c}{ Postoperative group } & \multirow{2}{*}{ p value } \\
\cline { 3 - 4 } & group & \multicolumn{1}{c}{$1 \mathrm{y}$} & $2 \mathrm{y}$ & \\
\hline Mean JOA score & $13.8 \pm 4.1$ & $22.2 \pm 4.0$ & $21.7 \pm 3.9$ & $<0.001$ \\
Mean VAS score for LBP & $8.68 \pm 1.4$ & $2.94 \pm 1.6$ & $2.98 \pm 1.6$ & $<0.001$ \\
& & & & \\
Mean VAS score for leg & $8.58 \pm 1.4$ & $2.72 \pm 1.4$ & $2.80 \pm 1.3$ & $<0.001$ \\
& & & & \\
Mean DH & $8.0 \pm 1.3$ & $12.0 \pm 1.6$ & $11.4 \pm 1.6$ & $<0.001$ \\
Mean WHL & $50.1 \pm 1.5$ & $55.8 \pm 1.8$ & $55.6 \pm 1.9$ & $<0.001$ \\
Mean WA & $7.5 \pm 2.4$ & $2.6 \pm 1.3$ & $2.4 \pm 1.2$ & $<0.001$ \\
\hline
\end{tabular}

All values are mean \pm standard deviation. The statistical analysis is a result between preoperative and 2 years later assessment. DH: disc height, JOA: Japanese Orthopaedic Association, LBP: lower back pain, VAS: visual analog scale, WA: vertebral wedge angle, WHL: whole lumbar lordosis, y: year.

series. But 128 of 142 patients obtained bony fusion according to previous fusion criteria. The solid fusion rate was $90.1 \%$. The mean fusion interval was 6.1 months (range, 4-11 months). At the 1-year follow-up, artificial cage subsidence of greater than $2 \mathrm{~mm}$ was observed in 7 of the 142 patients $(4.9 \%)$. Although cage subsidence is a known problem following lumbar interbody fusion, it was not correlated with the recurrence of symptoms or the radiographic fusion rate. We did not recognize the significant difference for bony fusion and clinical result by the kind of artificial disc cages.

The mean operation time for L4-5 was 155.5 min (range, 96-280 $\mathrm{min}$ ) and the average length of hospitalization was 6.9 days (range, 3-21 days). The mean blood loss was $63.7 \mathrm{ml}$ (range, 10-456 ml) without transfusion (Table 4). The complication rate was $2.8 \%$ (4/142), and cases included wound infection, liquorrhea due to a dural tear injury, vertebral body fractures needing a posterior pedicle screw fixation, and a misplaced cage that required revision. The mean 2-year postoperative JOA and VAS scores for the back and leg in the two reoperative cases were recovered by 6,5 , and 6 points compared with the preoperative state, respectively. The neurological condition did not worsen in any cases.

We performed the discography in all 45 disc disease patients and 23 of 30 spondylolisthesis patients. Provocative sign at L4-5 level showed $58.6 \%$ (42 patients of 45 disc disease and 2 of 30 spondylolisthesis). In these patients, postoperative JOA and VAS scores for lower back and leg pain improved siginificantly; provocative discoghraphic diagnosis was superior to other radiographic findings.
Table 4 Summary of mean operative data

\begin{tabular}{ll}
\hline Parameter & \\
\hline Procedural time in min (range) & $155.5(96-280)$ \\
Blood loss in ml (range) & $63.7(10-456)$ \\
Length of hospitalization in days (range) & $6.9(3-21)$ \\
\hline
\end{tabular}

I. Case example: A 65-year-old female in suboptimal health presented with a 5-year history of severe lower back pain and progressive neurogenic claudication. Preoperative imaging revealed degenerative intervertebral collapse and mild canal stenosis at multilumbar levels. The L4-5 lesion was found to correspond with concordant lower back pain via discography carried out during a left-sided miniALIF procedure, which restored spinal alignment and neuroforaminal height, indirectly decompressing the spinal nerves and obviating a posterior approach. The procedure was performed in $98 \mathrm{~min}$ with an estimated blood loss of up to $55 \mathrm{ml}$. The hospitalization period was 6 days. Twenty-four months after the mini-ALIF was performed (Fig. 1), the patient reported no preoperative lower back pain or neurogenic claudication.

\section{Discussion}

In some instances, lower back pain is secondary to degenerative spinal conditions; for such patients, lumbar fusion has been shown to be suitable and cost-effective. ${ }^{49,50)}$ ALIF including discectomy offers the advantage of anterior column support in the correction of lumbar lordosis and deformity without disturbing either back muscles or nerve roots. It also places the cage graft in compression, allowing it to 

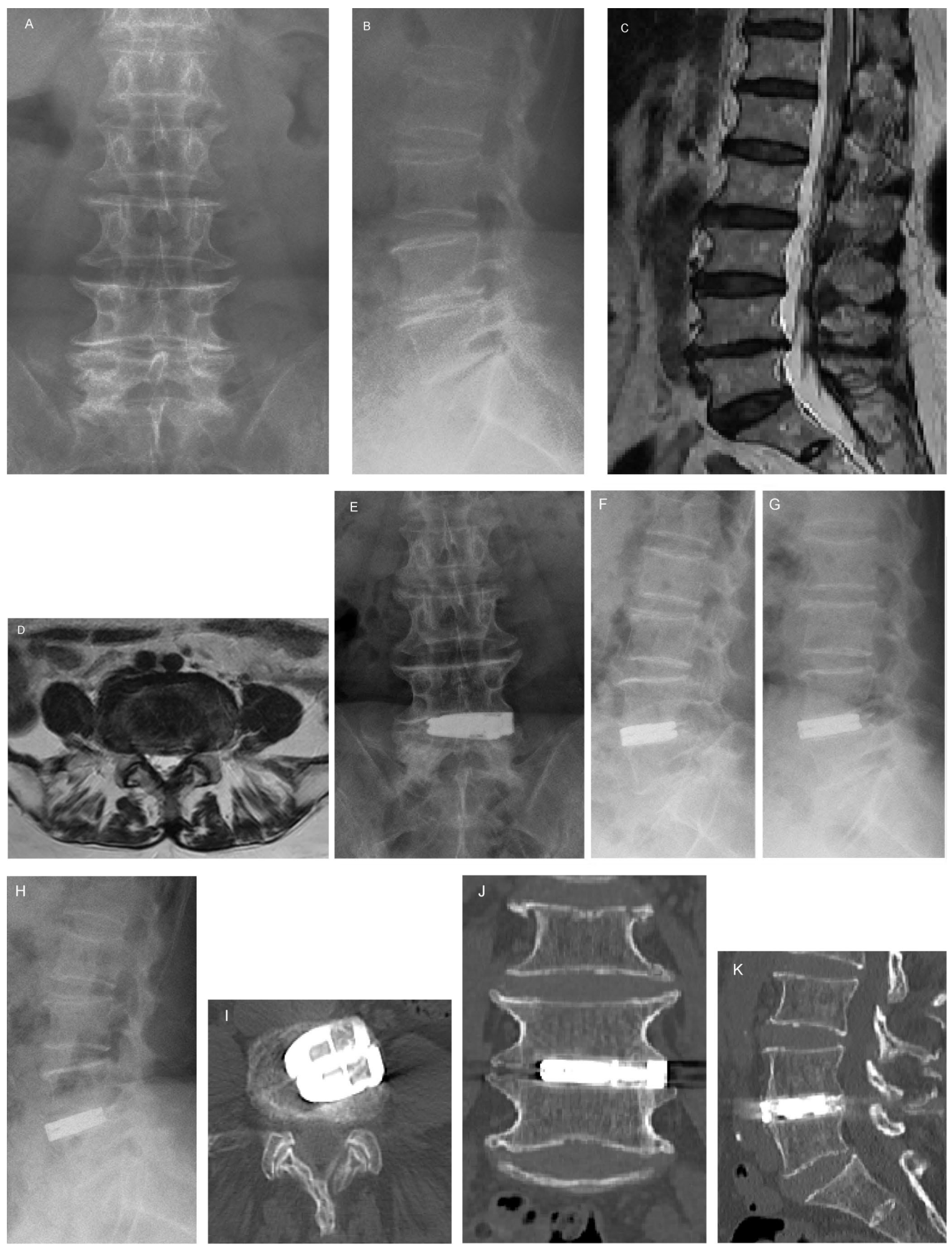

Fig. 1 Anteroposterior, lateral radiographs, $T_{2}$-weighted sagittal, and axial magnetic resonance (MR) images demonstrating the development of lumbar degenerative disorder in a patient who underwent minimally invasive anterior lumbar interbody fusion (mini-ALIF). Preoperative anteroposterior view radiographs (A), lateral view (B) and $\mathrm{T}_{2}$-weighted sagittal (C), and axial (D) MR images show L4-5 disc-space collapse without dynamic instability or canal lesions. Postoperative anteroposterior view radiographs (E), lateral view radiographs (F), flexion lateral view radiographs (G), extension lateral view radiographs $(H)$, axial view computed tomography (CT) scan images (I), coronal CT scan images (J), and sagittal CT scan images (K) were acquired 2 years after mini-ALIF. 
fuse more readily for improved initial stability of the fusion construct. Mayer and Wiechert ${ }^{32,33)}$ found this technique to be associated with low postoperative morbidity, negligible wound pain, low intraoperative blood loss, short operating time, and preliminary fusion results.

Biomechanical studies have suggested that standalone interbody cages are very stable in flexion and lateral bending, but that stability in extension and rotation is poor. ${ }^{38)}$ While stand-alone fixed cases may be insufficient in more serious instances, it is necessary to include more rigid fixation such as pedicle screw and anterior plating combined. There is no serious instability requiring additional rigid fixation in this series. It makes success to select our preoperative adequate evaluation and perform fine microsurgical maneuver.

The past clinical data on stand-alone mini-ALIF have shown no significant correlation between clinical outcome and fusion rate. ${ }^{52)}$ Reports of fusion success for stand-alone ALIF procedures in the literature range from $76 \%$ to $100 \%$. $^{2,9,13,16,17,23,26-29,31,32)}$ $\mathrm{Li}$ et al. ${ }^{29)}$ only reported that the fusion success rate was $57.5 \%$ according to their strict fusion criteria. Meanwhile our clinical report showed the correlation between satisfied result and high fusion rate. Some errors may be observed by the various criteria. Our high fusion success rate seems with an acceptable result within the limits of classical criteria. Greenough et al. ${ }^{15)}$ reported that patients treated with AILF had good-to-excellent outcomes compared with those undergoing posterior lumbar interbody fusion (PLIF) with pedicle screws. A retrospective review by Pradhan et al. ${ }^{39)}$ showed that single-level ALIF reduced operative blood loss, operative time, and hospitalization length, and improved the fusion rate compared with PLF with pedicle screw fixation. However, there were no significant differences in radiographic fusion rates, complication rates, or clinical outcomes. ${ }^{39)}$ Similarly, Strube et al. ${ }^{46)}$ showed that the same fusion rate and significantly better clinical outcome of stand-alone ALIF group compared with another group of ALIF with transpedicle fixation. ALIF is superior to transforaminal lumbar interbody fusion (TLIF) in its capacity to restore foraminal height, local disc angle, and lordosis, thereby potentially improving sagittal balance and leading to better long-term outcomes. ${ }^{25)}$ However, Barnes et al. ${ }^{1)}$ and Hacker $^{22)}$ reported that PLIF provided better patient outcomes and osseous fusion rates and shorter operative time, blood loss, and length of stay compared with ALIF. The latter therefore appears to be a particularly useful method for patients with back pain and radiculopathy without a herniated disc or important posterior compression..$^{25)}$

For failed back surgery, ALIF provides an approach through virgin tissue, thus avoiding the dissection of perineural scar tissue, and the retraction of scarred nerve roots and dura. ${ }^{11)}$ Moreover, complications associated with posterior revision lumbar surgery, including cerebrospinal fluid leaks, can be avoided, ${ }^{3,11)}$ whereas dural tears and neurologic injury are common in PLIF procedures. ${ }^{10)}$ The retroperitoneal anterior approach to anterior column reconstruction offers advantages over traditional anterior and posterior approaches to the lumbar spine; it does not require a general surgeon to perform the work, does not retract or violate the peritoneum, eliminates the need for mobilization of the great vessels, and preserves anterior and posterior longitudinal ligaments. ${ }^{50)}$

Many patients with degenerative disorder of the lumbar spine consider laparoscopic ALIF to be the least invasive approach. This is particularly true for L4-5 ALIF procedures. ${ }^{51)}$ Smith et al. ${ }^{45}$ reported that a mini-open approach had clinical as well as cost benefits over the open approach, with similar long-term outcomes and complication rates. Postoperative medical problems and infection appear to be minimized with a mini-open technique compared with the traditional open procedure, ${ }^{37)}$ presumably because of the smaller incisions and minimal disruption of the surrounding anatomy. ${ }^{50)}$ Mini-open ALIF is used in the current work as we consider it to be more precise than inexperienced laparoscopic procedures and superior to standard open ALIF.

The complication profile of 600 extreme lateral interbody fusion patients was recently assessed by Rodgers et al. ${ }^{43)}$ Operative complications occurred in $6.2 \%$ of patients, and 11 events $(1.8 \%)$ resulted in additional procedures or reoperation. There were no major complications including vascular or visceral injuries in this series. Indeed, the ALIF rate of complications has generally been reported to be less than $10 \%,,^{39,41,43,44,47,49-51)}$ with the exception of $38.3 \%$ reported by Rajaraman et al. ${ }^{40)}$ In our current series, the postoperative $\mathrm{DH}$, lordosis, and disc WA were statistically improved compared with the preoperative state. The clinical outcomes of our study also corresponded well to those reported in earlier studies, and 125 of 142 patients (88\%) experienced an excellent-to-good prognosis. This agreed well with the $78 \%$ reported by Mayer et al. ${ }^{33)}$

The ALIF procedure is technically demanding and is associated with disadvantages such as risk of injury to the greater/segmental vessels, common iliac vein, inferior vena cava, iliolumbar vein, retrograde ejaculation, pseudoarthrosis, subsidence, ileus, and lymphocele. ${ }^{725)}$ Regan et al. ${ }^{41)}$ reported 
the incidence of complications as $4.2 \%$ following open anterior lumbar surgery in 942 patients, who most commonly experienced thrombophlebitis, urinary retention, and warm-leg sensations. Garg et al. ${ }^{14)}$ found a significantly increased risk of vascular injury when two spinal levels were instrumented in male patients. Retrograde ejaculation resulting from injury to the superior hypogastric plexus had a reported incidence of $0.42 \%$ in a series of 4,500 open anterior approaches, with $25-50 \%$ of occurrences being transient. ${ }^{7,12)}$ There were no sexual complications in our series even though we reported greater vessel injury than other studies. Nevertheless, retroperitoneal anterolateral approaches to the lumbar spine might be more useful than standard anterior and posterior approaches in younger men of reproductive age.

The role of discography in evaluating pathologic discs has been controversial. ${ }^{30,36)}$ Several authors ${ }^{6,24,30,48)}$ have suggested that patients without symptomatic lower back problems might exhibit pain upon injection into the discs, particularly if they have degenerative changes. Greenspan et al. ${ }^{18)}$ found discography to be more useful for patients with normal MRI findings and continuing symptoms, whereas Guyer and Ohnmeiss ${ }^{21)}$ recommended discography as a diagnostic tool for the evaluation of abnormal discs, especially in patients with persistent severe symptoms in whom other diagnostic tests had failed. ${ }^{30)}$ However, some authors believe that patients with back pain and positive provocative discography are unlikely to have other nondiscogenic causes of lower back pain. ${ }^{5,6,30,44,48)}$ Madan et al. ${ }^{30)}$ considered provocative discography to be of limited efficacy in improving clinical outcome scores after lower back surgery for discogenic back pain. Colhoun et al ${ }^{8)}$ reported an $89 \%$ favorable result following fusion in patients with abnormal disc morphology and a concordant pain response compared with a $52 \%$ favorable rate in patients with abnormal disc morphology alone.

In our present study, the precise identification rate by discography was almost $60 \%$. As the postoperative JOA and VAS scores for lower back and leg pain were improved over those for the preoperative condition, discography appeared to be a helpful technique in cases with provocative discogenic pain. However, in spondylolisthesis, foraminal stenosis, and facet lesion, the cause of pain is rarely identified. In several recent studies, discography has been shown to have a role in the evaluation of patients with lower back pain; however, this seems to be limited to the evaluation of abnormal MRI interspaces, the investigation of adjacent-level disc disease, and ruling out cases of nonorganic pain from a surgical consideration. ${ }^{42)}$

Although the current study emphasized the role of mini-ALIF via the retroperitoneal approach, standard ALIF, PLIF, and TLIF are suitable alternative cures to correct the rootlessness of the lumbar vertebral body. The main limitation of our study was that it analyzed mini-ALIF cases retrospectively. A treatment-result comparison study using different approaches, such as PLIF and TLIF, is now required.

\section{Conflicts of Interest Disclosure}

The authors report no conflict of interest concerning the materials or methods used in this study or the finding specified in this article.

\section{References}

1) Barnes B, Rodts GE, McLaughkin MR, Haid RW Jr.: Threaded cortical bone dowels for lumbar interbody fusion: over 1-year mean follow up in 28 patients. J Neurosurg 95(1 Suppl): 1-4, 2001

2) Bohlman HH, Eismont FJ: Surgical techniques of anterior decompression and fusion for spinal cord injuries. Clin Orthop Relat Res 57-67, 1981

3) Brodke DS, Dick JC, Kunz DN, McCabe R, Zdeblick TA: Posterior lumbar interbody fusion. A biomechanical comparison, including a new threaded cage. Spine 22: 26-31, 1997

4) Carpenter N: Spondylolisthesis. Br J Surg 19: 374-386, 1932

5) Carragee EJ, Chen Y, Tanner CM, Truong T, Lau E, Brito JL: Provocative discography in patients after limited lumbar discectomy: a controlled, randomized study of pain response in symptomatic and asymptomatic subjects. Spine 25: 3065-3071, 2000

6) Carragee EJ, Tanner CM, Khurana S, Hayward C, Welsh J, Date E, Truong T, Rossi M, Hagle C: The rates of false-positive lumbar discography in select patients without low back symptoms. Spine 25: 1373-1380; discussion 1381, 2000

7) Choi JY, Choi YW, Sung KH: Anterior lumbar interbody fusion in patients with a previous discectomy: minimum 2-year follow-up. J Spinal Disord Tech 18: 347-352, 2005

8) Colhoun E, McCall IW, Williams L, Cassar Pullicino VN: Provocation discography as a guide to planning operations on the spine. J Bone Joint Surg Br 70: 267-271, 1988

9) Crock HV: Anterior lumbar interbody fusion: indications for its use and notes on surgical technique. Clin Orthop Relat Res 157-163, 1982

10) DiPaola CP, Molinari RW: Posterior lumbar interbody fusion. J Am Acad Orthop Surg 16: 130-139, 2008

11) Duggal N, Mendiondo I, Pares HR, Jhawar BS, Das K, Kenny KJ, Dickman CA: Anterior lumbar interbody fusion for treatment of failed back surgery syndrome: an outcome analysis. Neurosurgery 54: 636-643; 
discussion 643-644, 2004

12) Flynn JC, Price CT: Sexual complications of anterior fusion of the lumbar spine. Spine 9: 489-492, 1984

13) Fujimaki A, Crock HV, Bedbrook GM: The results of 150 anterior lumbar interbody fusion operations performed by two surgeons in Australia. Clin Orthop Relat Res 164-167, 1982

14) Garg J, Woo K, Hirsch J, Bruffey JD, Dilley RB: Vascular complications of exposure for anterior lumbar interbody fusion. J Vasc Surg 51: 946-950; discussion 950, 2010

15) Greenough CG, Peterson MD, Hadlow S, Fraser RD: Instrumented posterolateral lumbar fusion. Results and comparison with anterior interbody fusion. Spine 23: 479-486, 1998

16) Greenough CG, Taylor LJ, Fraser RD: Anterior lumbar fusion: results, assessment techniques and prognostic factors. Eur Spine J 3: 225-230, 1994

17) Greenough CG, Taylor LJ, Fraser RD: Anterior lumbar fusion. A comparison of noncompensation patients with compensation patients. Clin Orthop Relat Res 30-37, 1994

18) Greenspan A, Amparo EG, Gorczyca DP, Montesano PX: Is there a role for diskography in the era of magnetic resonance imaging? Prospective correlation and quantitative analysis of computed tomographydiskography, magnetic resonance imaging, and surgical findings. J Spinal Disord Tech 5: 26-31, 1992

19) Gertzbein SD, Court-Brown CM, Jacobs RR, Marks P, Martin C, Stoll J, Fazl M, Schwartz M, Rowed D: Decompression and circumferential stabilization of unstable spinal fractures. Spine 13: 892-895, 1988

20) Grob D, Scheier HJ, Dvorak J, Siegrist H, Rubeli M, Joller R: Circumferential fusion of the lumbar and lumbosacral spine. Arch Orthop Trauma Surg 111: 20-25, 1991

21) Guyer RD, Ohnmeiss DD: Lumbar discography. Position statement from the North American Spine Society Diagnostic and Therapeutic Committee. Spine 20: 2048-2059, 1995

22) Hacker RJ: Comparison of interbody fusion approaches for disabling low back pain. Spine 22: 660-665; discussion 665-666, 1997

23) Harmon PH: Anterior excision and vertebral body fusion operation for intervertebral disk syndromes of the lower lumbar spine: three-to five-year results in 244 cases. Clin Orthop Relat Res 26: 107-127, 1963

24) Holt EP: The question of lumbar discography. $J$ Bone Joint Surg Am 50: 720-726, 1968

25) Hsieh PC, Koski TR, O’Shaughnessy BA, Sugrue P, Salehi S, Ondra S, Liu JC: Anterior lumbar interbody fusion in comparison with transforaminal lumbar interbody fusion: implications for the restoration of foraminal height, local disc angle, lumbar lordosis, and sagittal balance. J Neurosurg Spine 7: 379-386, 2007

26) Inoue $\mathrm{S}$, Watanabe $\mathrm{T}$, Hirose $\mathrm{A}$, Tanaka $\mathrm{T}$, Matsui $\mathrm{N}$, Saegusa O, Sho E: Anterior discectomy and interbody fusion for lumbar disc herniation. A review of 350 cases. Clin Orthop Relat Res 183: 22-31, 1984

27) Kozak JA, O’Brien JP: Simultaneous combined anterior and posterior fusion. An independent analysis of a treatment for the disabled low-back pain patient. Spine 15: 322-328, 1990

28) Leong JC, Hooper G, Fang D, Chun SY: Disc excision and anterior spinal fusion for lumbar disc protrusion in the adolescent. Spine 7: 623-626, 1982

29) Li J, Dumonski ML, Liu Q, Lipman A, Hong J, Yang N, Jin Z, Ren Y, Limthongkul W, Bessy JT, Thalgott J, Gebauer G, Albert TJ, Vaccaro AR: A multicenter study to evaluate the safety and efficacy of a standalone anterior carbon $\mathrm{I} / \mathrm{F}$ cage for anterior lumbar interbody fusion: two-year results from a food and drug administration investigational device exemption clinical trial. Spine (Phila $P a$ 1976) 35 : E1564-1570, 2010

30) Madan S, Gundanna M, Harley JM, Boeree NR, Sampson M: Does provocative discography screening of discogenic back pain improve surgical outcome? J Spinal Disord Tech 15: 245-251, 2002

31) Maiman DJ, Pintar F, Yoganandan N, Reinartz J: Effects of anterior vertebral grafting on the traumatized lumbar spine after pedicle screw-plate fixation. Spine 18: 2423-2430, 1993

32) Mayer HM: A new microsurgical technique for minimally invasive anterior lumbar interbody fusion. Spine 22: 691-699; discussion 700, 1997

33) Mayer HM, Wiechert K: Microsurgical anterior approaches to the lumbar spine for interbody fusion and total disc replacement. Neurosurgery 51(5 Suppl): 159-165, 2002

34) Morimoto T: Anterior lumbar interbody fusion; ALIF. Neurosurgery Now No. 4. MEDICAL VIEW, Tokyo, pp 188-198, 2008

35) Morimoto T, Koshimae N, Nagata K, Hironaka Y, Tei R, Inui T: [Surgical treatment of degenerative lumbar spinal disorders: discography-oriented selection for surgical method]. Jpn J Neurosurg 14: 386-391, 2005 (Japanese)

36) Nachemson A: Lumbar discography-where are we today? Spine 14: 555-557, 1989

37) O'Toole JE, Eichholz KM, Fessler RG: Surgical site infection rates after minimally invasive spinal surgery. J Neurosurg Spine 11: 471-476, 2009

38) Oxland TR, Lund T: Biomechanics of stand-alone cages and cages in combination with posterior fixation: a literature review. Eur Spine J 9(Suppl 1): S95-101, 2000

39) Pradhan BB, Nassar JA, Delamarter RB, Wang JC: Single-level lumbar spine fusion: a comparison of anterior and posterior approaches. J Spinal Disord Tech 15: 355-361, 2002

40) Rajaraman V, Vingan R, Roth P, Heary RF, Conklin L, Jacobs G: Visceral and vascular complications resulting from anterior lumbar interbody fusion. J Neurosurg 91(1 Suppl): 60-64, 1999

41) Regan JJ, Yuan H, McAfee PC: Laparoscopic fusion of the lumbar spine: minimally invasive spine 
surgery. A prospective multicenter study evaluating open and laparoscopic lumbar fusion. Spine 24: 402-411, 1999

42) Resnick DK, Choudhri TF, Dailey AT, Groff MW, Khoo L, Matz PG, Mummaneni P, Watters WC, Wang J, Walters BC, Hadley MN; American Association of Neurological Surgeons/Congress of Neurological Surgeons: Guidelines for the performance of fusion procedures for degenerative disease of the lumbar spine. Part 6: magnetic resonance imaging and discography for patient selection for lumbar fusion. J Neurosurg Spine 2: 662-669, 2005

43) Rodgers WB, Gerber EJ, Patterson J: Intraoperative and early postoperative complications in extreme lateral interbody fusion: an analysis of 600 cases. Spine 36: 26-32, 2011

44) Schwarzer AC, Aprill CN, Derby R, Fortin J, Kine G, Bogduk N: The prevalence and clinical features of internal disc disruption in patients with chronic low back pain. Spine 20: 1878-1883, 1995

45) Smith WD, Christian G, Serrano S, Malone KT: A comparison of perioperative charges and outcome between open and mini-open approaches for anterior lumbar discectomy and fusion. J Clin Neurosci 19: 673-680, 2012

46) Strube P, Hoff E, Hartwig T, Perka CF, Gross C, Putzier M: Stand-alone anterior versus anteroposterior lumbar interbody single-level fusion after a mean follow-up of 41 months. J Spinal Disord Tech 25: 362-369, 2012

47) Tsutsumimoto T, Shimogata M, Yoshimura Y, Misawa
H: Union versus nonunion after posterolateral lumbar fusion: a comparison of long-term surgical outcomes in patients with degenerative lumbar spondylolisthesis. Eur Spine J 17: 1107-1112, 2008

48) Walsh TR, Weinstein JN, Spratt KF, Lehmann TR, Aprill C, Sayre H: Lumbar discography in normal subjects. A controlled, prospective study. J Bone Joint Surg Am 72: 1081-1088, 1990

49) Wang MY, Cummock MD, Yu Y, Trivedi RA: An analysis of the differences in the acute hospitalization charges following minimally invasive versus open posterior lumbar interbody fusion. J Neurosurg Spine 12: 694-699, 2010

50) Youssef JA, McAfee PC, Patty CA, Raley E, DeBauche S, Shucosky E, Chotikul L: Minimally invasive surgery: lateral approach interbody fusion: results and review. Spine 35(26 Suppl): 302-311, 2010

51) Zdeblick TA, David SM: A prospective comparison of surgical approach for anterior L4-L5 fusion: laparoscopic versus mini anterior lumbar interbody fusion. Spine 25: 2682-2687, 2000

52) Zhang JD, Poffyn B, Sys G, Uyttendaele D: Are stand-alone cages sufficient for anterior lumbar interbody fusion? Orthop Surg 4: 11-14, 2012

Address reprint requests to: Yasuo Hironaka, MD, Department of Neurosurgery, Nara Medical University, 840 Shijo-cho, Kashihara, Nara 634-8522, Japan. e-mail: hironaka@naramed-u.ac.jp 